\title{
EVALUASI PENGANGKUTAN SAMPAH DI KOTA PONTIANAK
}

\author{
Sri Lestari ${ }^{1)}$, Siti Nurlaily ${ }^{2)}$, Yulisa Fitrianingsih ${ }^{1)}$ \\ ${ }^{1)}$ Program Studi Teknik Lingkungan Jurusan Teknik Sipil Fakultas Teknik Universitas Tanjungpura, Pontianak \\ ${ }^{2)}$ Program Studi Teknik Sipil Jurusan Teknik Sipil Fakultas Teknik Universitas Tanjungpura, Pontianak \\ Email: taritarrii@gmail.com
}

\begin{abstract}
ABSTRAK
Pontianak merupakan ibukota daerah Kalimantan Barat yang memiliki jumlah penduduk sekitar 587.169 jiwa (BPS, 2014). Pertambahan jumlah penduduk sangat mempengaruhi terjadinya masalah sampah yaitu perubahan pola konsumsi dan gaya hidup masyarakat yang dapat meningkatkan jumlah timbulan sampah, jenis, dan keberagaman karakteristik sampah. Meningkatnya volume timbulan sampah memerlukan pengelolaan. Pengelolaan sampah yang diselenggarakan oleh dinas kebersihan berfokus kepada pengumpulan dan pengangkutan ke Tempat Pembuangan Akhir (TPA). Alat pengangkutan sampah yang memadai akan dapat mengangkut seluruh sampah kota. Namun, jumlah alat pengangkutan sampah berupa arm roll yang dimiliki oleh dinas kebersihan saat ini hanya sebanyak 18 unit (Dinas Kebersihan, 2014). Jumlah tersebut belum cukup untuk mengangkut semua sampah yang ada di Kota Pontianak dan menyebabkan banyak sampah yang tertinggal di lokasi TPS. Penelitian ini bertujuan untuk mengetahui pola pengangkutan sampah di Kota Pontianak saat ini dan mengetahui manajemen pengangkutan sampah yang berkaitan dengan jumlah alat pengangkutan sampah dan ritasi pengangkutan sampah sesuai dengan volume sampah yang dihasilkan, serta mengetahui rute alternatif pengambilan sampah per kecamatan yang efektif di Kota Pontianak saat ini.

Metode yang digunakan dalam pengambilan data adalah dengan cara observasi, studi literatur, dan studi dokumentasi. Observasi dilakukan di 6 kecamatan yang ada di Kota Pontianak. Pada tiap kecamatan dipilih 2 titik lokasi kontainer berdasarkan jarak terdekat dan terjauh dari lokasi TPA Batu Layang. Jadi, banyaknya titik lokasi kontainer yang digunakan sebagai sampel dalam penelitian ini berjumlah 12 titik. Dalam pengambilan sampel menggunakan metode Stratified sampling. Stratified sampling adalah perilaku pemberian tingkatan atau kelas pada data yang dipilih secara acak berdasarkan jarak terdekat dan terjauh dari lokasi TPA.

Hasil penelitian ini menunjukkan bahwa pola pengangkutan yang digunakan di Kota Pontianak saat ini menggunakan sistem HCS (Hauled Container System) dan manajemen pengangkutan sampah di Kota Pontianak masih belum optimal karena adanya kekurangan jumlah alat penangkutan sampah berupa arm roll sebanyak 13 unit dengan ritasi pengangkutan menjadi 6 ritasi per hari. Penambahan jumlah arm roll sebanyak 13 unit dan peningkatan ritasi pengangkutan menjadi 6 ritasi per hari pada setiap pengangkutan menyebabkan semua sampah di Kota Pontianak dapat terangkut dengan baik dan tidak ada yang tersisa.
\end{abstract}

Kata Kunci: Sampah, Pola Pengangkutan, Alat Pengangkutan

ABSTRACT

Pontianak is the capital city of West Borneo which has the rate of residents about 587.169 people (BPS, 2014). The increasing number population strongly affects the appearance of wastage issue that is the change of consumption pattern and people's lifestyle which can rise the amount of waste pile, types, and the range of wastage characteristics. The increasing of wastage pile volume needs a cultivation. Wastage cultivation perfoming by Sanitary Department focuses on collecting and transporting the wastage to the final site of dispossal or well-known as Tempat Pembuangan Akhir (TPA). Ideal equipments to carry the wastage can carry the whole waste in the city. However, the number of the equipments like arm roll owned only by the Sanitary Department nowadays is only about 18 units (Dinas Kebersihan, 2014). This number is insufficient to carry all the wastage in the city of Pontianak and it causes a large amount of wastage left in the TPS site. This research aims to know the wastage transport pattern in Pontianak city todays and to know the wastage transport management related to the number of transport equipment and the ritasi of the wastage transport based on the 
volume of wastage resulted, as well as knowing the alternative route of taking out the wastage in each subdistrict effectively in Pontianak city nowadays.

The method used in this data sampling is observation, literature study and documentation. The observation was conducted in six different subdistricts located in Pontianak City. In each subdistrict, the researcher selected two coordinate of container locations based on the nearest and the furtherst distance the TPA location in Batu Layang. Therefore, the number of point of the container location used in research sample is 12 points. In taking the sample, the researcher used stratified sampling. This sampling technique is the giving the level or class on the data randomly selected based on the nearest and furtherest location from TPA.

The result of this research shows that the pattern of transport used in Pontianak city recently utilizes HSC system (Hauled Container System) and wastage transport management in Pontianak city is not optimal yet inasmuch as the shortage of wastage transport equipments in form of arm roll with the number only 13 units and the increasing number of transport ritasi to 6 rit per day on each transport. The additional number of arm roll around 13 units and the increase of ritasi to 6 per day on each of the transport cause all the wastage in Pontianak city could be properly carried and there was no remaining.

Keywords : Wastage, Pattern of Transport, Transport Equipment

\section{PENDAHULUAN}

Pontianak merupakan ibukota daerah Kalimantan Barat yang memiliki jumlah penduduk sekitar 587.169 jiwa (BPS, 2014). Pertambahan jumlah penduduk sangat mempengaruhi terjadinya masalah sampah yaitu perubahan pola konsumsi dan gaya hidup masyarakat yang dapat meningkatkan jumlah timbulan sampah, jenis, dan keberagaman karakteristik sampah. Meningkatnya volume timbulan sampah memerlukan pengelolaan. Pengelolaan sampah yang diselenggarakan oleh dinas kebersihan berfokus kepada pengumpulan dan pengangkutan ke Tempat Pembuangan Akhir (TPA).

Ketersediaan jumlah alat pengangkutan sampah sangat berpengaruh terhadap keberhasilan pengelolaan sampah kota. Alat pengangkutan sampah yang memadai akan dapat mengangkut seluruh sampah kota. Namun, jumlah alat pengangkutan sampah berupa arm roll yang dimiliki oleh dinas kebersihan saat ini hanya sebanyak 18 unit (Dinas Kebersihan, 2014). Jumlah tersebut belum cukup untuk mengangkut semua sampah yang ada di Kota Pontianak dan menyebabkan banyak sampah yang tertinggal di lokasi TPS.

Berdasarkan permasalahan dalam sistem pengangkutan sampah tersebut, maka penulis ingin menyusun suatu evaluasi pengangkutan sampah di Kota Pontianak. Sehingga dapat diketahui bagaimana tingkat keefektifan dalam pengangkutan sampah tersebut.

\section{METODOLOGI PENELITIAN}

\section{A. Tempat dan Waktu Penelitian}

Lokasi penelitian ini berada di wilayah Kota Pontianak Provinsi Kalimantan Barat dan waktu yang diperlukan dalam penelitian tentang evaluasi pengangkutan sampah di kota Pontianak ini berlangsung dari bulan Februari 2014 hingga Juli 2014.

\section{B. Data Primer}

Data primer adalah data yang diperoleh secara langsung melalui observasi / pengamatan langsung di lapangan. Pengumpulan data primer dalam penelitian ini dilakukan dengan survey lokasi penelitian, pengamatan lokasi penempatan kontainer, pengukuran lama waktu pengisian dan pengosongan sampah pada kontainer, pengukuran lama waktu perjalanan, jarak perjalanan pengamatan fasilitas pengangkutan, dan rute perjalanan. 


\section{Data Sekunder}

Data sekunder yang dikumpulkan dalam penelitian ini adalah data yang berkaitan dengan daerah pelayanan, data jumlah penduduk, jumlah dan penempatan kontainer, jumlah alat pengangkutan sampah berupa dump truck dan arm roll, serta peta rute pengangkutan. Data diperoleh dari Dinas Kebersihan dan Pertamanan Kota Pontianak.

\section{Teknik Analisa Data}

Dalam metode penelitian ini yang pertama dilakukan adalah pengumpulan data primer yang berguna untuk melengkapi kebutuhan data penelitian. Teknik pengumpulan data tersebut menggunakan metode observasi / pengamatan langsung di lapangan. Observasi dimulai dengan melihat langsung lokasi peletakan kontainer yang ada di Kota Pontianak. Setelah itu diambil 12 titik lokasi kontainer sebagai sampel dalam penelitian ini. Pengambilan sampel dalam penelitian ini menggunakan metode stratified sampling. Stratified sampling adalah perilaku pemberian tingkatan atau kelas pada data yang dipilih secara acak berdasarkan jarak terdekat dan terjauh dari lokasi TPA. Kemudian semua data tersebut dianalisis menggunakan berbagai rumus yang didapat melalui studi literatur. Dari pengamatan dan perhitungan yang telah dilakukan dapat diketahui pola pengangkutan yang terdapat di Kota Pontianak, jumlah alat pengangkutan sampah yang dibutuhkan, serta ritasi pengangkutan yang sesuai di Kota Pontianak saat ini.

\section{E. Teknik Pengumpulan Data}

Dalam penelitian ini, penulis menggunakan beberapa metode yaitu observasi, studi literatur, dan studi dokumentasi. Observasi dilakukan dengan mengadakan pengamatan langsung di lapangan untuk mendapatkan data-data yang diperlukan mengenai proses pengangkutan sampah di Kota Pontianak. Studi Literatur, yaitu metode pengumpulan data dan informasi dengan mempergunakan literatur-literatur yang sesuai dengan permasalahan yang diteliti pada proses pengangkutan di Kota Pontianak. Studi Dokumentasi yaitu mengumpulkan data-data dari dokumen yang tersedia di kantor kebersihan.

\section{ANALISIS DAN PEMBAHASAN}

\section{A. Pola Pengangkutan Sampah}

Metode pengangkutan sampah di Kota Pontianak menggunakan sistem HCS (Hauled Container System) yaitu sistem pengumpulan sampah yang wadah pengumpulannya dapat dipindah-pindah dan ikut dibawa ke tempat pembuangan akhir. Pada sistem HCS ini, pola pengangkutan yang digunakan adalah pola pengosongan kontainer, dimana truk arm roll yang berisi kontainer kosong akan dibawa menuju TPS dan menukarnya dengan kontainer yang telah terisi penuh. Berikut adalah contoh pengangkutan sampah di Kota Pontianak yang menggunakan sistem HCS:

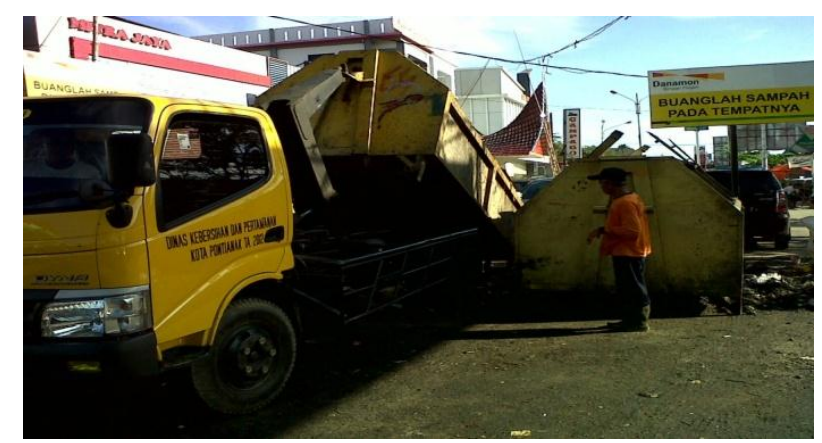

Gambar 1 Contoh Pengangkutan Sampah di Kecamatan Pontianak Kota 
Data hasil pengamatan di lapangan dipaparkan pada tabel 1 sebagai berikut:

Tabel 1 Data Hasil Pengamatan

\begin{tabular}{|c|c|c|c|c|c|c|c|c|c|c|}
\hline Kecamatan & \multicolumn{2}{|c|}{ Lokasi TPS } & \multirow{2}{*}{$\begin{array}{c}\begin{array}{c}x \\
(\mathbf{k m})\end{array} \\
59,6 \\
\end{array}$} & \multirow{2}{*}{$\begin{array}{c}\begin{array}{c}y \\
(\mathrm{~km} / \mathrm{jam})\end{array} \\
41 \\
\end{array}$} & \multirow{2}{*}{$\begin{array}{l}\text { pc } \\
\text { (s) }\end{array}$} & \multirow{2}{*}{$\begin{array}{l}\text { uc } \\
\text { (s) }\end{array}$} & \multirow{2}{*}{$\begin{array}{c}\mathrm{dbc} \\
(\mathrm{s}) \\
240 \\
\end{array}$} & \multirow{2}{*}{$\begin{array}{c}\mathbf{s} \\
(\mathbf{s}) \\
120 \\
\end{array}$} & \multirow{2}{*}{$\begin{array}{c}\mathbf{W} \\
0,15 \\
\end{array}$} & \multirow{2}{*}{$\begin{array}{c}\begin{array}{c}t_{1}+t_{2} \\
\text { (menit) }\end{array} \\
108 \\
\end{array}$} \\
\hline Pontianak Barat & Jl. Komyos Sudarso & Dekat Pasar Nipah Kuning & & & & & & & & \\
\hline & Jl. Komyos Sudarso & Depan Gg. Saga & 49,4 & 41 & 70 & 50 & 240 & 110 & 0,15 & 94 \\
\hline \multirow[t]{2}{*}{ Pontianak Selatan } & Jl. Letkol Sugiono & Gor Pangsuma & 49,8 & 40 & 84 & 62 & 350 & 112 & 0,15 & 93 \\
\hline & Jl. Imam Bonjol & Depan Gg. Garuda & 42 & 40 & 74 & 58 & 350 & 106 & 0,15 & 85 \\
\hline \multirow[t]{2}{*}{ Pontianak Kota } & Jl. Dr. Wahidin & Sepakat Ujung & 57,2 & 41 & 71 & 56 & 466 & 102 & 0,15 & 110 \\
\hline & Jl. AR. Hakim & Belakang PSP & 47,2 & 40 & 72 & 57 & 466 & 100 & 0,15 & 96 \\
\hline \multirow[t]{2}{*}{ Pontianak Tenggara } & Komplek UNTAN & Sepakat 2/Rusunawa & 45 & 40 & 85 & 65 & 464 & 102 & 0,15 & 87 \\
\hline & Jl. Dr. Soedarso & Komp. RSUD Soedarso & 36,4 & 40 & 82 & 62 & 464 & 121 & 0,15 & 78 \\
\hline \multirow[t]{2}{*}{ Pontianak Timur } & Jl. Tanjung raya II & Samping Gg. Mutiara & 23,8 & 40 & 69 & 45 & 208 & 105 & 0,15 & 56 \\
\hline & Jl. Tanjung Raya I & Tanjung Hilir & 20,4 & 41 & 68 & 43 & 208 & 108 & 0,15 & 40 \\
\hline \multirow[t]{2}{*}{ Pontianak Utara } & Jl. Khatulistiwa & Depan Gg. Usaha Baru & 6,4 & 41 & 98 & 76 & 576 & 114 & 0,15 & 28 \\
\hline & Jl. 28 Oktober & Depan Gg. Swasembada V & 18,4 & 41 & 94 & 70 & 576 & 112 & 0,15 & 48 \\
\hline
\end{tabular}

Sumber: Hasil Pengamatan, 2014

Ket:

$\mathrm{x}=$ Jarak rute pulang pergi

$\mathrm{y}=$ Kecepatan rata-rata

$\mathrm{pc}=$ Waktu menaikkan kontainer isi uc = Waktu menurunkan kontainer kosong

$\mathrm{dbc}=$ Waktu antar TPS

$\mathrm{s} \quad=$ Waktu bongkar muat di TPA
W = Waktu hambatan

$\mathrm{t}_{1}+\mathrm{t}_{2}=$ Waktu pengangkutan per 1 ritasi 


\section{B. Analisis Pengangkutan Sampah dengan Sistem HCS}

Untuk mengetahui waktu per ritasi pada proses pengangkutan sampah $\left(T_{H C S}\right)$, terlebih dahulu dilakukan perhitungan haul time (h).

- Haul time (h)

Nilai $\mathrm{h}$ diperoleh dari perbandingan antara jarak rute pulang pergi $(x)$ dengan kecepatan rata-rata (y).

Tabel 2. Hubungan Jarak Rute Pulang Pergi (x), Kecepatan Rata-Rata (y), dengan Haul Time (h)

\begin{tabular}{|c|c|c|c|c|c|}
\hline Kecamatan & \multicolumn{2}{|c|}{ Lokasi TPS } & $\begin{array}{c}x \\
(\mathrm{~km})\end{array}$ & $\begin{array}{c}y \\
\text { (km/iam) }\end{array}$ & $\begin{array}{c}\mathrm{h} \\
\text { (iam) }\end{array}$ \\
\hline \multirow[t]{2}{*}{ Pontianak Barat } & Jl. Komyos Sudarso & Dekat Pasar Nipah Kuning & 59,6 & 41 & 1,45 \\
\hline & Jl. Komyos Sudarso & Depan Gg. Saga & 49,4 & 41 & 1,20 \\
\hline \multirow[t]{2}{*}{ Pontianak Selatan } & Jl. Letkol Sugiono & Gor Pangsuma & 49,8 & 40 & 1,25 \\
\hline & Jl. Imam Bonjol & Depan Gg. Garuda & 42 & 40 & 1,05 \\
\hline \multirow[t]{2}{*}{ Pontianak Kota } & Jl. Dr. Wahidin & Sepakat Ujung & 57,2 & 41 & 1,40 \\
\hline & Jl. AR. Hakim & Belakang PSP & 47,2 & 40 & 1,18 \\
\hline \multirow[t]{2}{*}{ Pontianak Tenggara } & Komplek UNTAN & Sepakat 2/Rusunawa & 45 & 40 & 1,13 \\
\hline & Jl. Dr. Soedarso & Komp. RSUD Soedarso & 36,4 & 40 & 0,91 \\
\hline \multirow[t]{2}{*}{ Pontianak Timur } & Jl. Tanjung raya II & Samping Gg. Mutiara & 23,8 & 40 & 0,60 \\
\hline & Jl. Tanjung Raya I & Tanjung Hilir & 20,4 & 41 & 0,50 \\
\hline \multirow[t]{2}{*}{ Pontianak Utara } & Jl. Khatulistiwa & Depan Gg. Usaha Baru & 6,4 & 41 & 0,16 \\
\hline & Jl. 28 Oktober & Depan Gg. Swasembada V & 18,4 & 41 & 0,45 \\
\hline \multicolumn{6}{|c|}{ Ket : $\square$ hasil pengukuran } \\
\hline
\end{tabular}

Sumber : Hasil Pengukuran dan Perhitungan

Dari perhitungan di atas diperoleh nilai $\mathrm{h}$ adalah sebesar $1,45 \mathrm{jam}$. Untuk nilai $\mathrm{h}$ pada titik berikutnya digunakan perhitungan yang sama sehingga tidak dituliskan kembali.

- $\quad \mathbf{P}_{\text {HCS }}$ (Waktu Pengambilan)

Waktu pengambilan kontainer isi dan peletakkan kontainer kosong disebut dengan $\mathrm{P}_{\text {HCS. }}$ Untuk menghitung nilai $P_{\text {HCS }}$ digunakan persamaan 3.5. Nilai $P_{\text {HCS }}$ di tiap lokasi TPS ditampilkan pada tabel $\mathbf{3}$ sebagai berikut: 
Tabel 3. Perhitungan Nilai $P_{\text {HCS }}$

\begin{tabular}{|c|c|c|c|c|c|c|}
\hline Kecamatan & \multicolumn{2}{|c|}{ Lokasi TPS } & $\begin{array}{l}\text { pc } \\
\text { (s) }\end{array}$ & $\begin{array}{l}\text { uc } \\
\text { (s) }\end{array}$ & $\begin{array}{l}\text { dbc } \\
\text { (s) }\end{array}$ & $\begin{array}{l}\text { PHCS } \\
\text { (s) }\end{array}$ \\
\hline \multirow[t]{2}{*}{ Pontianak Barat } & Jl. Komyos Sudarso & Dekat Pasar Nipah Kuning & 80 & 60 & 240 & 380 \\
\hline & Jl. Komyos Sudarso & Depan Gg. Saga & 70 & 50 & 240 & 360 \\
\hline \multirow[t]{2}{*}{ Pontianak Selatan } & Jl. Letkol Sugiono & Gor Pangsuma & 84 & 62 & 350 & 496 \\
\hline & Jl. Imam Bonjol & Depan Gg. Garuda & 74 & 58 & 350 & 482 \\
\hline \multirow[t]{2}{*}{ Pontianak Kota } & JI. Dr. Wahidin & Sepakat Ujung & 71 & 56 & 466 & 593 \\
\hline & JI. AR. Hakim & Belakang PSP & 72 & 57 & 466 & 595 \\
\hline \multirow[t]{2}{*}{ Pontianak Tenggara } & Komplek UNTAN & Sepakat 2/Rusunawa & 85 & 65 & 464 & 614 \\
\hline & Jl. Dr. Soedarso & Komp. RSUD Soedarso & 82 & 62 & 464 & 608 \\
\hline \multirow[t]{2}{*}{ Pontianak Timur } & Jl. Tanjung raya II & Samping Gg. Mutiara & 69 & 45 & 208 & 322 \\
\hline & Jl. Tanjung Raya I & Tanjung Hilir & 68 & 43 & 208 & 319 \\
\hline \multirow[t]{2}{*}{ Pontianak Utara } & Jl. Khatulistiwa & Depan Gg. Usaha Baru & 98 & 76 & 576 & 750 \\
\hline & Jl. 28 Oktober & Depan Gg. Swasembada V & 94 & 70 & 576 & 740 \\
\hline \multicolumn{2}{|c|}{ Ket: $\square$ hasil pengukuran } & $\square$ hasil perhitungan & & & & \\
\hline
\end{tabular}

Sumber : Hasil Pengukuran dan Perhitungan

Dari perhitungan di atas diperoleh nilai $\mathrm{P}_{\text {HCS }}$ sebesar 206 detik. Untuk nilai $\mathrm{P}_{\text {HCS }}$ pada titik berikutnya digunakan perhitungan yang sama sehingga tidak dituliskan kembali.

- $\quad \mathbf{T}_{\text {HCS }}$ (Waktu per Ritasi)

Waktu yang diperlukan untuk mengangkut kontainer dari TPS menuju TPA untuk satu kali

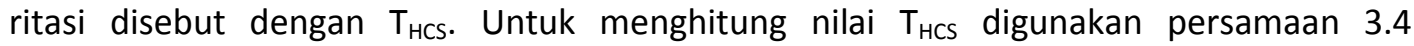
berdasarkan nilai h pada tabel 2 dan nilai $P_{H C S}$ pada tabel 3. Hasil perhitungan nilai $T_{H C S}$ ditampilkan pada tabel 4 sebagai berikut:

Tabel 4 Perhitungan Nilai $\mathrm{T}_{\text {HCS }}$

\begin{tabular}{|c|c|c|c|c|c|c|}
\hline \multirow{2}{*}{$\begin{array}{r}\text { Kecamatan } \\
\text { Pontianak Barat } \\
\end{array}$} & \multicolumn{2}{|c|}{ Lokasi TPS } & \multirow{2}{*}{$\begin{array}{c}\begin{array}{c}S \\
(s)\end{array} \\
120 \\
\end{array}$} & \multirow{2}{*}{$\begin{array}{c}\begin{array}{c}\mathbf{h} \\
\text { (jam) }\end{array} \\
1,45 \\
\end{array}$} & \multirow{2}{*}{$\begin{array}{c}\text { PHCS } \\
\text { (s) } \\
380 \\
\end{array}$} & \multirow{2}{*}{$\begin{array}{r}\text { THCS } \\
\text { (jam) } \\
1,59 \\
\end{array}$} \\
\hline & Jl. Komyos Sudarso & Dekat Pasar Nipah Kuning & & & & \\
\hline & Jl. Komyos Sudarso & Depan Gg. Saga & 110 & 1,20 & 360 & 1,34 \\
\hline \multirow[t]{2}{*}{ Pontianak Selatan } & Jl. Letkol Sugiono & Gor Pangsuma & 112 & 1,25 & 496 & 1,41 \\
\hline & Jl. Imam Bonjol & Depan Gg. Garuda & 106 & 1,05 & 482 & 1,21 \\
\hline \multirow[t]{2}{*}{ Pontianak Kota } & Jl. Dr. Wahidin & Sepakat Ujung & 102 & 1,40 & 593 & 1,59 \\
\hline & Jl. AR. Hakim & Belakang PSP & 100 & 1,18 & 595 & 1,37 \\
\hline \multirow[t]{2}{*}{ Pontianak Tenggara } & Komplek UNTAN & Sepakat 2/Rusunawa & 102 & 1,13 & 614 & 1,32 \\
\hline & Jl. Dr. Soedarso & Komp. RSUD Soedarso & 121 & 0,91 & 608 & 1,11 \\
\hline \multirow[t]{2}{*}{ Pontianak Timur } & Jl. Tanjung raya II & Samping Gg. Mutiara & 105 & 0,60 & 322 & 0,71 \\
\hline & Jl. Tanjung Raya I & Tanjung Hilir & 108 & 0,50 & 319 & 0,62 \\
\hline \multirow[t]{2}{*}{ Pontianak Utara } & Jl. Khatulistiwa & Depan Gg. Usaha Baru & 114 & 0,16 & 750 & 0,40 \\
\hline & Jl. 28 Oktober & Depan Gg. Swasembada V & 112 & 0,45 & 740 & 0,69 \\
\hline \multicolumn{7}{|c|}{$\begin{array}{ll}\text { Ket : } & \square \text { hasil pengukuran } \\
& \square \text { hasil perhitungan }\end{array}$} \\
\hline
\end{tabular}

Sumber : Hasil Pengukuran dan Perhitungan 
Dari perhitungan di atas diperoleh nilai $T_{\text {HCS }}$ sebesar $1,59 \mathrm{jam} / \mathrm{rit}$. Untuk nilai $\mathrm{T}_{\text {HCS }}$ pada titik berikutnya digunakan perhitungan yang sama sehingga tidak dituliskan kembali.

- $\quad$ Nd (Jumlah Ritasi per Hari)

Jumlah ritasi per kendaraan per hari yang dibutuhkan untuk mengangkut kontainer dari TPS menuju TPA disebut dengan Nd. Untuk menghitung nilai Nd digunakan persamaan 3.6 berdasarkan nilai $W$ dan nilai $t_{1}+t_{2}$ pada tabel 1 dan nilai $T_{H C S}$ pada tabel 4 dan diasumsikan bahwa waktu kerja per hari adalah 8 jam. Hasil perhitungan nilai $\mathrm{Nd}$ ditampilkan pada tabel $\mathbf{5}$ sebagai berikut:

Tabel 5 Perhitungan Nilai Nd

\begin{tabular}{|c|c|c|c|c|c|c|}
\hline \multirow{2}{*}{$\begin{array}{c}\text { Kecamatan } \\
\text { Pontianak Barat }\end{array}$} & \multicolumn{2}{|c|}{ Lokasi TPS } & \multirow{2}{*}{$\frac{\mathbf{W}}{0,15}$} & \multirow{2}{*}{$\begin{array}{c}\frac{\mathrm{t} 1+\mathrm{t} 2}{\text { (menit) }} \\
108\end{array}$} & \multirow{2}{*}{$\begin{array}{c}\begin{array}{c}\text { THCS } \\
\text { (jam) }\end{array} \\
1,59 \\
\end{array}$} & \multirow{2}{*}{$\begin{array}{c}\begin{array}{c}\text { Nd } \\
\text { (rit/hari) }\end{array} \\
3\end{array}$} \\
\hline & Jl. Komyos Sudarso & Dekat Pasar Nipah Kuning & & & & \\
\hline & Jl. Komyos Sudarso & Depan Gg. Saga & 0,15 & 94 & 1,34 & 4 \\
\hline \multirow[t]{2}{*}{ Pontianak Selatan } & Jl. Letkol Sugiono & Gor Pangsuma & 0,15 & 93 & 1,41 & 4 \\
\hline & Jl. Imam Bonjol & Depan Gg. Garuda & 0,15 & 85 & 1,21 & 4 \\
\hline \multirow[t]{2}{*}{ Pontianak Kota } & Jl. Dr. Wahidin & Sepakat Ujung & 0,15 & 110 & 1,59 & 3 \\
\hline & Jl. AR. Hakim & Belakang PSP & 0,15 & 96 & 1,37 & 4 \\
\hline \multirow[t]{2}{*}{ Pontianak Tenggara } & Komplek UNTAN & Sepakat 2/Rusunawa & 0,15 & 87 & 1,32 & 4 \\
\hline & Jl. Dr. Soedarso & Komp. RSUD Soedarso & 0,15 & 78 & 1,11 & 5 \\
\hline \multirow[t]{2}{*}{ Pontianak Timur } & Jl. Tanjung raya II & Samping Gg. Mutiara & 0,15 & 56 & 0,71 & 8 \\
\hline & Jl. Tanjung Raya I & Tanjung Hilir & 0,15 & 40 & 0,62 & 10 \\
\hline \multirow[t]{2}{*}{ Pontianak Utara } & Jl. Khatulistiwa & Depan Gg. Usaha Baru & 0,15 & 28 & 0,40 & 16 \\
\hline & Jl. 28 Oktober & Depan Gg. Swasembada V & 0,15 & 48 & 0,69 & 9 \\
\hline \multicolumn{5}{|c|}{ Rata-Rata } & 1,11 & 6 \\
\hline \multicolumn{7}{|c|}{ Ket : $\begin{array}{l}\square \text { hasil pengukuran } \\
\text { hasil perhitungan }\end{array}$} \\
\hline
\end{tabular}

Sumber : Hasil Pengukuran dan Perhitungan

Dari perhitungan di atas diperoleh nilai Nd pada lokasi Jalan Komyos Sudarso (Dekat Pasar Nipah Kuning) sebanyak 3 ritasi per hari. Untuk nilai Nd pada titik berikutnya digunakan perhitungan yang sama sehingga tidak dituliskan kembali. Kemudian didapatkan nilai Nd ratarata sebanyak 6 ritasi per hari.

\section{Analisis Kebutuhan Alat Angkut}

Berdasarkan tabel 5 dan asumsi lama jam kerja perhari adalah 8 jam dan 1 ritasi memerlukan waktu rata-rata 1,11 jam maka dalam 1 hari maksimal ritasi yang dapat dilakukan adalah 6 ritasi per hari. Perbandingan jumlah ritasi, volume sampah terangkut, tak terangkut dan tingkat pelayanan ditampilkan pada tabel 6 sebagai berikut: 
Tabel 6 Kebutuhan Jumlah Alat Angkut

\begin{tabular}{|c|c|c|c|c|c|c|}
\hline $\begin{array}{c}\text { Jumlah } \\
\text { Ritasi }\end{array}$ & $\begin{array}{c}\text { Volume } \\
\text { Sampah } \\
\left(\mathbf{m}^{\mathbf{3}} \mathbf{\text { hari} )}\right.\end{array}$ & $\begin{array}{c}\text { Volume } \\
\text { Kontainer } \\
\left(\mathbf{m}^{\mathbf{3}} \mathbf{)}\right.\end{array}$ & $\begin{array}{c}\text { Jumlah Alat } \\
\text { Angkut } \\
\text { (unit) }\end{array}$ & $\begin{array}{c}\text { Volume Sampah } \\
\text { Terangkut } \\
\left(\mathbf{m}^{\mathbf{3}} \mathbf{/ h a r i}\right)\end{array}$ & $\begin{array}{c}\text { Volume Sampah } \\
\text { Tersisa } \\
\left(\mathbf{m}^{\mathbf{3}} / \mathbf{h a r i}\right)\end{array}$ & $\begin{array}{c}\text { Persentase } \\
\text { Pelayanan }\end{array}$ \\
\hline 1 & $1.107,88$ & 6 & 18 & 108 & 999,88 & $10 \%$ \\
\hline 2 & $1.107,88$ & 6 & 18 & 216 & 891,88 & $19 \%$ \\
\hline 3 & $1.107,88$ & 6 & 18 & 324 & 783,88 & $29 \%$ \\
\hline 4 & $1.107,88$ & 6 & 18 & 432 & 675,88 & $39 \%$ \\
\hline 5 & $1.107,88$ & 6 & 18 & 540 & 567,88 & $49 \%$ \\
\hline 6 & $1.107,88$ & 6 & 18 & 648 & 459,88 & $58 \%$ \\
\hline
\end{tabular}

Sumber: Hasil Analisis, 2014

Berdasarkan Tabel 6, volume sampah yang dihasilkan di Kota Pontianak adalah sebanyak $1.107,88 \mathrm{~m}^{3} /$ hari. Alat angkut yang dimiliki oleh dinas kebersihan sebanyak 18 unit arm roll yang berkapasitas $6 \mathrm{~m}^{3}$ hanya dapat mengangkut sampah sebanyak $648 \mathrm{~m}^{3} /$ hari dengan 6 kali ritasi per hari.

Oleh karena itu, masih terdapat sampah yang tidak terangkut sebanyak $459,88 \mathrm{~m}^{3} /$ hari. Maka untuk mengangkut sisa sampah tersebut dengan menggunakan sistem HCS diperlukan penambahan alat angkut. Jumlah penambahan alat angkut yang diperlukan dapat dihitung dengan perhitungan sebagai berikut:

Alat angkut $=$ Vol sampah tak terangkut $:$ vol kontainer $:$ ritasi

Alat angkut $=459,88 \mathrm{~m}^{3} /$ hari : $6 \mathrm{~m}^{3}: 6 \mathrm{rit} /$ hari

Alat angkut $=13$ unit

Jadi, untuk mengangkut sampah Kota Pontianak yang volumenya mencapai $1.107,88$ $\mathrm{m}^{3} /$ hari dibutuhkan penambahan jumlah alat angkut berupa arm roll sebanyak 13 unit dengan ritasi pengangkutan menjadi 6 rit/hari.

\section{Rute Pengangkutan Sampah}

Dari evaluasi di lapangan, penulis mengambil sampel data rute pengangkutan sampah yang berawal dari pool hingga ke TPS hingga kembali ke TPA. Rute ini diambil berdasarkan pengamatan yang dilakukan pada 12 titik pengangkutan sampah yang ada di 6 kecamatan. Dari data yang diperoleh, dilakukan pencarian rute alternatif. Rute ini dibuat untuk mendapatkan jarak dan waktu pengangkutan sampah yang lebih pendek dari sebelumnya. Data rute hasil survey dan rute alternatif ditampilkan pada tabel sebagai berikut: 
Tabel 7 Rute Alternatif dengan Jarak Terpendek Pada 12 Lokasi Pengamatan

\begin{tabular}{|c|c|c|c|c|c|}
\hline Kecamatan & & Lokasi TPS & Rute & $\begin{array}{l}\text { Jarak } \\
(\mathrm{Km})\end{array}$ & $\begin{array}{l}\text { Waktu } \\
\text { (Menit) }\end{array}$ \\
\hline \multirow{2}{*}{$\begin{array}{l}\text { Pontianak } \\
\text { Barat }\end{array}$} & Jl. Komyos Sudarso & Dekat Pasar Nipah Kuning & $\begin{array}{l}\text { POOL(Dinas Kebersihan)-komyos Sudarso-TPS } 42 \text { (depan pasar nipah kuning)-Pak } \\
\text { Kasih-Tanjungpura-Imam Bonjol-Adisucipto-JEMBATAN KAPUAS 2-Tanjung Raya II- } \\
\text { Perintis Kemerdekaan-Budi Utomo-TPA }\end{array}$ & 58,4 & 93 \\
\hline & Jl. Komyos Sudarso & Depan Gg. Saga & $\begin{array}{l}\text { POOL(Dinas Kebersihan)-komyos Sudarso-TPS } 41 \text { (depan gg. Saga)-Pak Kasih- } \\
\text { Tanjungpura-Imam Bonjol-Adisucipto-JEMBATAN KAPUAS 2-Tanjung Raya II-Perintis } \\
\text { Kemerdekaan-Gusti Situt Mahmud-Budi Utomo-TPA }\end{array}$ & 48,2 & 85 \\
\hline \multirow{2}{*}{$\begin{array}{l}\text { Pontianak } \\
\text { Selatan }\end{array}$} & Jl. Letkol Sugiono & Gor Pangsuma & $\begin{array}{l}\text { POOL(TPA)-Letkol Sugiono-TPS } 30 \text { (Gor Pangsuma)-Ahmad Yani-Veteran-Imam } \\
\text { Bonjol-Adi Sucipto-JEMBATAN KAPUAS 2-Tanjung Raya II-Perintis Kemerdekaan-Gusti } \\
\text { Situt Mahmud-Khatulistiwa-Budi Utomo-TPA }\end{array}$ & 45,6 & 90 \\
\hline & Jl. Imam Bonjol & Depan Gg. Garuda & $\begin{array}{l}\text { POOL(TPA)-Imam Bonjol-TPS } 26 \text { (depan Gg. Garuda)-Adisucipto-JEMBATAN KAPUAS } \\
\text { 2-Tanjung Raya II-Perintis Kemerdekaan-Budi Utomo-TPA }\end{array}$ & 40,8 & 78 \\
\hline \multirow{2}{*}{$\begin{array}{l}\text { Pontianak } \\
\text { Kota }\end{array}$} & Jl. Dr. Wahidin & Sepakat Ujung & $\begin{array}{l}\text { POOL (Dinas Kebersihan)-Dr.Wahidin-TPS } 19 \text { (Sepakat Ujung)-Dr. Wahidin-Dr. } \\
\text { Sutomo-Sultan Syahrir-Sultan Abdurrahman-A.Yani-Veteran-Imam Bonjol-Adisucipto- } \\
\text { JEMBATAN KAPUAS 2-Tanjung Raya II-Perintis Kemerdekaan-Gusti Situt Mahmud- } \\
\text { Khatulistiwa-Budi Utomo-TPA }\end{array}$ & 56,8 & 101 \\
\hline & Jl. AR. Hakim & Belakang PSP & $\begin{array}{l}\text { POOL (Dinas Kebersihan)-AR. Hakim-TPS } 48 \text { (Belakang PSP)-Pattimura-Gajah Mada- } \\
\text { Pahlawan-Imam Bonjol-Adisucipto-JEMBATAN KAPUAS 2-Tanjung Raya II-Perintis } \\
\text { Kemerdekaan-Budi Utomo-TPA }\end{array}$ & 45,8 & 86 \\
\hline \multirow{2}{*}{$\begin{array}{l}\text { Pontianak } \\
\text { Tenggara }\end{array}$} & Komplek UNTAN & Sepakat 2/Rusunawa & $\begin{array}{l}\text { POOL(TPA)-Kompleks UNTAN-TPS } 50 \text { (Sepakat } 2 \text { / Rusunawa)-Bundaran Digulis- } \\
\text { Ahmad Yani II-JEMBATAN KAPUAS 2-Tanray II-Perintis Kemerdekaan-Gusti Situt } \\
\text { Mahmud-khatulistiwa-TPA }\end{array}$ & 43,6 & 80 \\
\hline & Jl. Dr. Soedarso & Komp. RSUD Soedarso & $\begin{array}{l}\text { POOL(TPA)-DR.Sudarso-TPS } 28 \text { (Komp. RSUD Sudarso)-Adisucipto-JEMBATAN KAPUAS } \\
\text { 2-Tanjung Raya II-Perintis Kemerdekaan-Gusti Situt Mahmud-Budi Utomo-TPA }\end{array}$ & 35,5 & 72 \\
\hline \multirow{2}{*}{$\begin{array}{l}\text { Pontianak } \\
\text { Timur }\end{array}$} & Jl. Tanjung raya II & Samping Gg. Mutiara & $\begin{array}{l}\text { POOL(TPA)-Tanjung Raya 2-TPS } 32 \text { (samping gg. Mutiara)-Perintis Kemerdekaan-Gusti } \\
\text { Situt Mahmud-khatulistiwa-Budi Utomo-TPA }\end{array}$ & 22,6 & 43 \\
\hline & Jl. Tanjung Raya I & Tanjung Hilir & $\begin{array}{l}\text { POOL(TPA)-Tanjung Raya I-TPS } 60 \text { (Tanjung Hilir)-Perintis Kemerdekaan-Gusti Situt } \\
\text { Mahmud-khatulistiwa-Budi Utomo-TPA }\end{array}$ & 19,2 & 37 \\
\hline \multirow{2}{*}{$\begin{array}{l}\text { Pontianak } \\
\text { Utara }\end{array}$} & JI. Khatulistiwa & Depan Gg. Usaha Baru & POOL(TPA)-Khatulistiwa-TPS 37 (Depan Gg. Usaha Baru)-Khatulistiwa-TPA & \multicolumn{2}{|c|}{ Tetap } \\
\hline & Jl. 28 Oktober & Depan Gg. Swasembada V & $\begin{array}{l}\text { POOL(TPA)-28 Oktober-TPS } 66 \text { (Depan Gg. Swasembada V)-Budi Utomo-Sungai } \\
\text { Selamat-TPA }\end{array}$ & 17 & 35 \\
\hline
\end{tabular}

Sumber: Data Analisis, 2014 


\section{REKOMENDASI}

Dari berbagai analisis yang telah disebutkan di atas, dapat direkomendasikan berbagai hal sebagai berikut:

1. Perlunya dilakukan penambahan jumlah alat pengangkutan sampah dan jumlah ritasi per hari agar proses pengangkutan sampah bisa lebih optimal dan sampah dapat terangkut dengan baik

2. Perlunya manajemen waktu yang baik bagi petugas pengangkut sampah agar mau melakukan proses pengangkutan lebih awal untuk menghindari kemacetan dan dapat menjalankan tugasnya sesuai waktu dan jadwal yang telah ditentukan

3. Sebaiknya diadakan penambahan jumlah TPA di lokasi yang jaraknya lebih dekat dari TPSTPS yang ada di Kota Pontianak agar pengangkutan sampah bisa dilakukan lebih cepat dan dapat mengurangi jumlah sampah yang dibuang ke TPA Batu Layang.

4. Perlu mengadakan koordinasi secara terpadu dari instansi yang bertanggungjawab dalam proses pengangkutan dan pengelolaan sampah dengan semua instansi dan masyarakat.

\section{KESIMPULAN}

Dari evaluasi pengangkutan sampah di Kota Pontianak yang telah dilakukan maka dapat disimpulkan bahwa:

1. Pola pengangkutan sampah yang digunakan di Kota Pontianak saat ini menggunakan sistem HCS (Hauled Container System) dengan pola pengosongan kontainer, dimana truk arm roll yang berisi kontainer kosong akan dibawa menuju TPS dan menukarnya dengan kontainer yang telah terisi penuh.

2. Manajemen pengangkutan sampah di Kota Pontianak masih belum optimal karena adanya kekurangan jumlah alat penangkutan sampah berupa arm roll sebanyak 13 unit dengan ritasi pengangkutan menjadi 6 ritasi per hari.

3. Kota Pontianak terdiri dari 6 kecamatan, yaitu Pontianak Kota, Pontianak Selatan, Pontianak Barat, Pontianak Timur, dan Pontianak Tenggara. Dari keenam kecamatan, Pontianak Kota, Pontianak Selatan, Pontianak Barat, Pontianak Timur, dan Pontianak Tenggara memiliki rute alternatif yang lebih efektif dati TPS menuju TPA dengan jarak terpendek dan waktu pengangkutan yang lebih singkat. Sedangkan pada Kecamatan Pontianak Utara (Jalan Khatulistiwa) tidak memiliki rute pengangkutan yang lebih efektif.

\section{Ucapan Terima Kasih}

Penulis mengucapkan terima kasih kepada Allah SWT., kedua orang tua yang telah memberikan dukungan secara moril dan materil, kepada ibu Siti Nurlaili, ST, MT dan ibu Yulisa Fitrianingsih, ST, MT selaku dosen pembimbing, kepada ibu Dian Rahayu Jati, ST, M.Si dan Bapak Hendri Sutrisno, ST, MT selaku dosen penguji, serta tidak lupa pula kepada temanteman Angaradasa angkatan 2010 Fakultas Teknik UNTAN yang banyak membantu dalam penyelesaian skripsi ini.

\section{Referensi}

Amien, M. Sjukrul. 2012. Materi Bidang Sampah I. Direktorat Jenderal Cipta Karya Kementerian Pekerjaan Umum.

BPS. 2014. Data Kota Pontianak dalam angka 2014. Badan Pusat Statistik. Pontianak

Dinas Kebersihan dan Pertamanan Kota Pontianak. 2014

Theisen, dkk. 1977. Solid Wastes Engeineering Principles and Management Issues. TokyoJapan: Mc. Graw-Hill Kogakusha Ltd. 